REGARDS

SUR L'ECONOMIE ALLEMAND

BULLETIN ECONOMIQUE DU CIRAC
Regards sur l'économie allemande

Bulletin économique du CIRAC

$104 \mid 2012$

Varia

\title{
Matières premières : l'industrie se mobilise
}

Isabelle Bourgeois

\section{OpenEdition}

\section{Journals}

Édition électronique

URL : http://journals.openedition.org/rea/4398

DOI : $10.4000 /$ rea.4398

ISBN : 978-2-8218-1286-4

ISSN : 1965-0787

Éditeur

CIRAC

Édition imprimée

Date de publication : 13 avril 2012

Pagination : 32-33

ISSN : 1156-8992

Référence électronique

Isabelle Bourgeois, "Matières premières : l'industrie se mobilise », Regards sur l'économie allemande [En ligne], 104 | avril 2012, mis en ligne le 17 avril 2012, consulté le 15 septembre 2020. URL : http:// journals.openedition.org/rea/4398

Ce document a été généré automatiquement le 15 septembre 2020

(C) CIRAC 


\title{
Matières premières : l'industrie se mobilise
}

\author{
Isabelle Bourgeois
}

\section{Une Alliance de grands industriels,...}

1 L'Alliance pour la sécurité de l'accès aux matières premières (Allianz zur Rohstoffsicherung) a été portée sur les fonds baptismaux le 30 janvier 2012. Ce groupement dont la mission est de sécuriser à terme l'approvisionnement des entreprises en matières premières menacées d'un risque de pénurie, grâce à leur accompagnement dès la phase d'exploration et à une présence mieux organisée sur les marchés producteurs, est présidé par Dierk Paskert, membre du directoire d'E.ON Energie AG (Munich).

\section{... préfiguration d'une société...}

2 Le financement initial de cette future société dont la structure institutionnelle comme l'organisation restent à définir est assurée par douze géants industriels : Aurubis, BASF, Bayer, BMW, Bosch, Chemetall, Daimler, Evonik Industries Georgsmarienhütte Holding, Stahl-Holding Saar, ThyssenKrupp et Wacker Chemie. Durant sa phase de développement, elle bénéficie du conseil gracieux de quatre grands cabinets : Boston Consulting Group, Egon Zehnder, Hovan Lovells et Pricewaterhouse- Coopers.

\section{...pour défendre les intérêts de l'industrie}

Cette Alliance, qui avait été conçue par un groupe de travail sous la direction d'Ulrich Grillo, vice-président de la Fédération de l'industrie BDI, est le fruit d'une longue et étroite coopération entre les principales fédérations sectorielles de l'industrie, engagée dès 2007. L'industrie allemande avait alors saisi l'occasion de l'attention médiatique portée à la double présidence allemande de l'UE et du G8 pour sensibiliser les 
entreprises et le pouvoir politique sur les risques pour la compétitivité que représentent les difficultés croissantes d'accès aux matières premières énergétiques et autres sur les marchés allemand, mais aussi mondiaux (voir REA 81/ 2007).

\section{Coopération étroite avec le gouvernement...}

4 Le gouvernement fédéral avait alors annoncé le 20 mars de la même année l'institution d'une commission interministérielle ad hoc (Interministerieller Ausschuss - IMA Rohstoffe), placée sous la houlette du ministère fédéral de l'Economie et chargée de définir des conditions-cadre créant un environnement favorable en Allemagne, et de plaider pour l'adoption de telles dispositions à l'échelon européen et mondial. Cette commission, constituée en juin 2007, élabore la politique allemande dans le domaine de l'approvisionnement en matières premières autres qu'énergétiques. La Fédération BDI, qui fait partie de la 'triade décisionnelle' associant gouvernement, partenaires sociaux et industrie, est de ce fait membre ès qualités de la commission IMA où elle fait valoir les intérêts de l'industrie.

\section{... et partage des responsabilités}

5 D'entrée, la question des matières premières, qui constitue une priorité à la fois pour le politique (préserver durablement la compétitivité du site Allemagne) et pour les industriels (garantir leur stratégie de compétitivité globale), est conçue comme ne pouvant être abordée que grâce à un partage des tâches, conformément au principe de subsidiarité. Gérer au mieux la production relève par définition des entreprises: " assurer l'approvisionnement en matières premières est avant toutes choses l'affaire de chaque entreprise ", ne cesse de rappeler le BDI, que ce soit dans ses prises de position publiques ou dans l'un des rapports stratégiques publiés depuis 2007 (ici, rapport de juin 2010 intitulé «Für eine strategische und ganzheitliche Rohstoffpolitik. BDI-Strategiepapier zur Rohstoffsicherheit "). Or, les entreprises étant impuissantes par nature face aux problèmes politiques des marchés, ceux-ci «appellent une réponse de la part des responsables gouvernementaux » (discours de Jürgen R. Thumann lors de l'ouverture du $2^{\mathrm{e}}$ congrès du BDI sur les matières premières, le 20 mars 2007). $A$ fortiori dans les instances communautaires et sur la scène internationale.

\section{Une approche globale de la compétitivité}

6 Le $3^{\mathrm{e}}$ congrès sur les matières premières, organisé par la fédération BDI le 26 octobre 2011, avait été l'occasion pour le gouvernement fédéral de présenter sa nouvelle stratégie politique (voir www.bmwi.de, rubrique Rohstoffpolitik). Elle avait été élaborée notamment sur la base d'un rapport d'évaluation des besoins des différentes branches commandé par le ministère fédéral de l'Economie à l'institut Fraunhofer ISI (Karlsruhe) et publié en février 2009 sous le titre "Matières premières pour les technologies d'avenir» ("Rohstoffe für Zukunftstechnologien»). Cette concentration sur quelques secteurs avait amené la fédération BDI à rappeler l'importance qu'accorde l'industrie à une approche résolument globale d'une telle politique, et à son étroite articulation avec les politiques européennes, mais aussi avec les enjeux géopolitiques. 
7 Voilà un exemple représentatif de l'acception allemande de la notion de 'politique industrielle' comme des mécanismes de prise de décision sur des dossiers stratégiques pour l'avenir de la compétitivité globale de l'économie. Son ressort est le partenariat institutionnel entre acteurs économiques et sphère politique qui permet de défendre les intérêts vitaux d'un secteur tout en veillant à l'intérêt général. La clé de ce dialogue constructif et établi dans la durée : une responsabilité partagée et assumée par tous les acteurs concernés, à commencer par les entreprises. IB

INDEX

Mots-clés : matière première, industrie, politique industrielle, entreprise, entreprise multinationale, compétitivité 